\title{
PESQUISA DE ATIVIDADE SULFITO REDUTASE EM LEVEDURAS DE ORIGEM ENOLÓGICA
}

\author{
Luciano NETO ; Ana Alexandra MENDES-FERREIRA**
}

\begin{abstract}
RESUMO
O sulfeto de hidrogênio $\left(\mathrm{H}_{2} \mathrm{~S}\right)$ é um produto secundário da fermentação alcoólica que possui um aroma desagradável a ovos podres. A quantidade de $\mathrm{H}_{2} \mathrm{~S}$ produzido durante a vinificação é influenciada pela estirpe de levedura utilizada e pela composição do mosto. Foi objetivo deste trabalho, avaliar a capacidade de produção de $\mathrm{H}_{2} \mathrm{~S}$ em leveduras indígenas de origem enológica e selecionar isolados pouco produtores de sulfeto. A atividade sulfito redutase foi pesquisada, em 259 leveduras isoladas de mostos e vinhos, no meio comercial BiGGY Agar. Os resultados demonstraram que as leveduras não Saccharomyces produziram mais $\mathrm{H}_{2} \mathrm{~S}$ que as leveduras do gênero Saccharomyces. A relação entre a produção de sulfeto de hidrogênio e a composição do mosto foi avaliada em 25 isolados pouco produtores de $\mathrm{H}_{2} \mathrm{~S}$ no meio comercial. Foram utilizados 11 mostos de uva e um mosto sintético de composição química definida, aos quais foi adicionado citrato de bismuto como indicador. Os resultados demonstram haver uma influência significativa da composição do mosto no potencial das leveduras para produzir $\mathrm{H}_{2} \mathrm{~S}$. O mosto natural com citrato de bismuto é um meio adequado para prever a capacidade de uma dada levedura produzir $\mathrm{H}_{2} \mathrm{~S}$ num determinado mosto.
\end{abstract}

Palavras-chave: leveduras; Saccharomyces cerevisiae; não Saccharomyces; sulfeto de hidrogênio; vinho.

\section{SUMMARY}

SCREENING OF SUPHITE REDUCTASE ACTIVITY IN WINE RELATED YEASTS. Hydrogen sulphide ( $\left.\mathrm{H}_{2} \mathrm{~S}\right)$ is a by-product of alcoholic fermentation that has an off-odour like rotten eggs. The amount of $\mathrm{H}_{2} \mathrm{~S}$ produced during winemaking is influenced by the yeast strain and must composition. The purpose of this work was to evaluate the ability of indigenous wine yeast to produce $\mathrm{H}_{2} \mathrm{~S}$, and select isolates low-sulphide producers. Sulphite reductase activity was screened in 259 isolates from musts and wines in BiGGY Agar Medium. The results demonstrate that non-Saccharomyces yeasts were higher $\mathrm{H}_{2} \mathrm{~S}$-producers than those strains of Saccharomyces used in this study. The relationship between $\mathrm{H}_{2} \mathrm{~S}$ production and medium composition was evaluated in 25 isolates that displayed low $\mathrm{H}_{2} \mathrm{~S}$ production on BiGGY Agar. For that, 11 natural grape musts and a chemically defined grape juice medium with bismuth citrate as indicator were used. The results demonstrate that the must composition influenced significantly the ability of the yeast to produce $\mathrm{H}_{2} \mathrm{~S}$. The use of natural grape juice with bismuth citrate as indicator is an adequate medium to predict the potential of a determined yeast strain to produce $\mathrm{H}_{2} \mathrm{~S}$ in a specific must.

Keywords: yeast; Saccharomyces cerevisiae; non-Saccharomyces; hydrogen sulphide; wine.

\section{1 - INTRODUÇÃO}

O sulfeto de hidrogênio $\left(\mathrm{H}_{2} \mathrm{~S}\right)$ é um produto secundário da fermentação alcoólica que possui aroma de ovos podres, cujo limiar de percepção num vinho neutro varia entre 50 e $80 \mu \mathrm{g} . \mathrm{L}$ [12]. Têm sido apontados numerosos fatores que condicionam a produção de $\mathrm{H}_{2} \mathrm{~S}$ durante a fermentação vínica: concentração em compostos nitrogenados; teor em compostos sulfurados; o estado de maturação da uva; as práticas enológicas; a taxa e a temperatura de fermentação; e a estirpe de levedura $[1,3,4,5,6,9$, $10,11,12,15,16,18,20]$. Sem dúvida, um dos fatores que se destaca pela sua importância, é a capacidade intrínseca da levedura para produzir $\mathrm{H}_{2} \mathrm{~S}[14,16,20]$. A produção de $\mathrm{H}_{2} \mathrm{~S}$ pelas leveduras envolve a incorporação do sulfato (SO) na célula e a sua redução (Figura 1) [16].

Recebido para publicação em 22/08/2003. Aceito para publicação em 18/05/2005(001196).

Depto. de Indústrias Alimentares, Centro de Genética e Biotecnologia, Universidade de Trás-os-Montes e Alto Douro, 5000911 Vila Real, Portugal. Telefone: +351259350 550. E-mail: anamf@utad.pt

A quem a correspondência deve ser enviada.
ZAMBONELLI, SOLLI \& GUERRA [20], observaram uma acumulação de sulfito em meios de cultura em que fermentações eram conduzidas por estirpes de Saccharomyces cerevisiae não produtoras de $\mathrm{H}_{2} \mathrm{~S}$, o que os levou a relacionar esta incapacidade para produzir $\mathrm{H}_{3} \mathrm{~S}$ com a ausência de atividade da enzima sulfito redutase.

ZAMBONELLI [19] utilizou um meio sólido contendo sulfito de bismuto para avaliar a capacidade de estirpes de leveduras para reduzir o sulfito a sulfeto. JIRANEK, LANGRIDGE \& HENSCHKE [8] validaram o emprego do meio comercial BiGGY Agar, que contém bismuto como indicador da formação de sulfeto, para avaliar o potencial de leveduras do vinho para produzir $\mathrm{H}_{2} \mathrm{~S}$. Os autores verificaram existir uma relação direta entre o escurecimento da colônia em BiGGY Agar e a capacidade da levedura para produzir $\mathrm{H}_{2} \mathrm{~S}$ durante a fermentação vínica. Mais tarde, MENDES-FERREIRA, MENDES-FAIA \& LEÃO [10], utilizando diversos mostos naturais e sintéticos com citrato de bismuto como indicador, constataram haver uma diferença significativa entre os resultados obtidos nos diversos meios e em BiGGY Agar, concluindo haver uma influência da composição do meio de cultura nos níveis de atividade sulfito redutase das diferentes estirpes comerciais estudadas. 


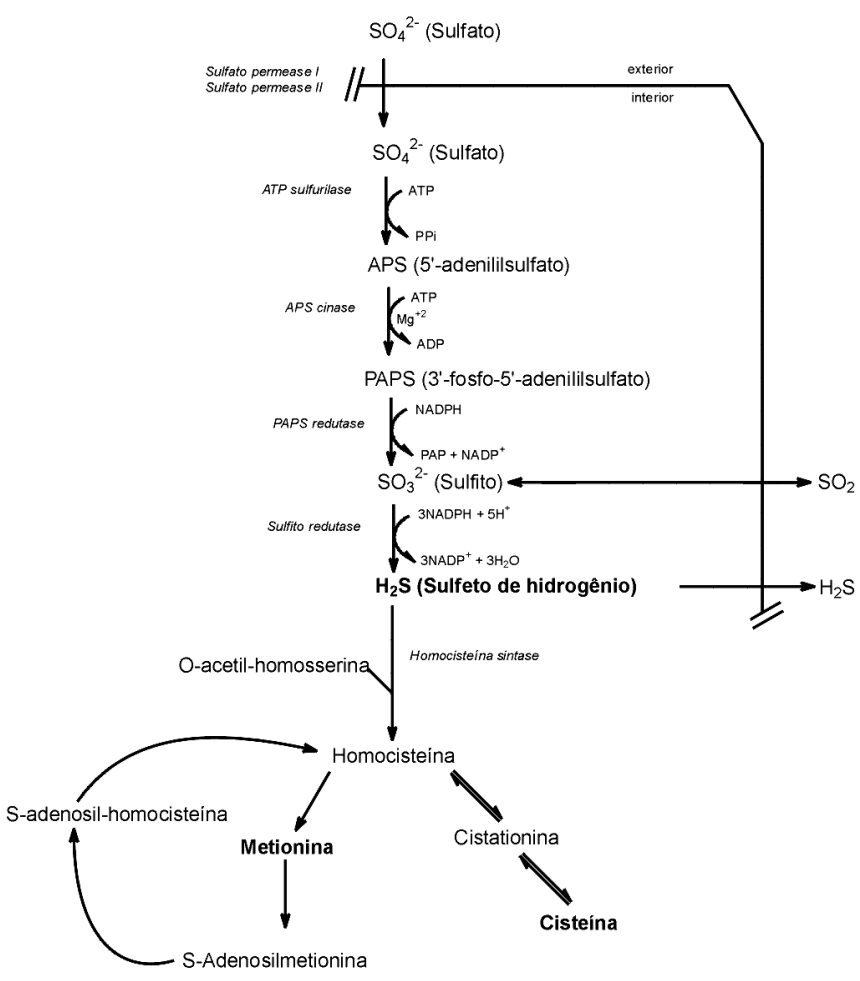

FIGURA 1 - Via de redução do sulfato em Saccharomyces cerevisiae

Pretendeu-se neste trabalho avaliar o potencial de leveduras indigenas de origem enológica para produzir $\mathrm{H}_{2} \mathrm{~S}$, no sentido de selecionar estirpes pouco ou não produtoras de sulfeto e, simultaneamente, avaliar o efeito da composição do meio de cultura na capacidade de produção de $\mathrm{H}_{2} \mathrm{~S}$ de estirpes previamente selecionadas como pouco produtoras.

\section{2 - MATERIAL E MÉTODOS}

\section{1 - Isolamento das leveduras}

Foram isoladas leveduras de mostos e vinhos da Região Demarcada do Douro, Portugal. Os isolamentos foram efetuados em meio de cultura WL Differential Medium (Difco). O meio de cultura foi preparado de acordo com as instruções do fabricante, suplementado com 0,5g.L' de cloranfenicol (Sigma).

Os isolados foram mantidos em tubos inclinados com meio YPD $(0,5 \%$ extracto de levedura, $1 \%$ peptona, $2 \%$ glucose e $2 \%$ agar) a $4^{\circ} \mathrm{C}$.

\section{2 - Identificação das leveduras}

Os isolados foram divididos em Saccharomyces e não-Saccharomyces utilizando-se Lysine Medium (Oxoid) e posteriormente identificados recorrendo-se à chave de identificação de leveduras associadas ao vinho e ao seu processo de elaboração, apresentado por BARNETT, PAYNE \& YARROW [2].

\section{3 - Avaliação da atividade sulfito redutase}

Para determinar o potencial para produzir $\mathrm{H}_{2} \mathrm{~S}$, em todas as leveduras, empregou-se o meio de cultura BiGGY Agar (Difco). Posteriormente, os isolados menos produtores de $\mathrm{H}_{2} \mathrm{~S}$ neste meio de cultura foram testados em mosto sintético de composição química definida (MS) e em 11 mostos naturais (M1 a M11) de uvas brancas e tintas da Região Demarcada do Douro, Portugal. O meio de cultura BiGGY Agar foi preparado de acordo com os procedimentos descritos pelo fabricante. O MS foi preparado de acordo com HENSCHKE \& JIRANEK [7] modificado por MENDES-FERREIRA, MENDES-FAIA \& LEÃO [10]. Após descongelação, os mostos naturais foram centrifugados (10.000rpm $\times 15 \mathrm{~min} \times 10^{\circ} \mathrm{C}$ ) e adicionados $11 \mathrm{~g} . \mathrm{L}$ de citrato de bismuto (Sigma) e 20g.L' de ágar (Difco). Os mostos foram, então, aquecidos até a completa dissolução do ágar e distribuídos em placas de Petri.

Após $24 \mathrm{~h}$ de crescimento a $25^{\circ} \mathrm{C}$ em meio de cultura YPD, os isolados foram repicados para os meios descritos acima e cultivados durante $48 \mathrm{~h}$ a $30^{\circ} \mathrm{C}$, sendo, em seguida, avaliada a cor da colônia no meio de cultura.

A avaliação qualitativa da produção de sulfeto ( $\mathrm{S}^{2}$ ) foi feita pela atribuição de um valor de uma escala arbitrária e contínua, entre 0 e 4, consoante a coloração da colônia no meio de cultura: branco (0), bege (1), marrom claro (2), marrom escuro (3) e preto (4).

\section{4 - Análise estatistica}

A análise de variância e a análise fatorial foram efetuadas utilizando o pacote estatístico SPSS (versão 8.0 para Windows, SPSS Inc.). Para efetuar a análise fatorial, a amostra foi avaliada quanto a sua adequação ao modelo pela medida de adequação da amostra de KaiserMeyer-Olkin (KMO) e pelo teste de esfericidade de Barlett (10). A análise fatorial foi efetuada utilizando-se o método de extração de componentes principais, tendo sido empregue o método de rotação VARIMAX com normalização de Kaiser.

\section{3 - RESULTADOS E DISCUSSÃO}

Foram isoladas 259 leveduras de mostos e vinhos, sendo 149 do gênero Saccharomyces e 110 de gêneros não Saccharomyces. A atividade sulfito redutase foi detectada em todos os isolados pesquisados, que apresentaram variado grau de escurecimento no meio de cultura BiGGY Agar. A maioria dos isolados pode ser considerada medianamente produtora de $\mathrm{H}_{2} \mathrm{~S}$, visto que apresentaram uma coloração entre marrom claro (2) e marrom escuro (3) no meio de cultura BiGGY Agar.

Em seu trabalho, ZAMBONELLI, SOLLI \& GUERRA [20] encontraram 1,1\% de estirpes de Saccharomyces não produtoras de $\mathrm{H}_{2} \mathrm{~S}$ entre 11800 testadas. Nesta pesquisa, encontrou-se uma freqüência semelhante à encontrada por estes autores dentre os isolados do gênero Saccharomyces, dos quais dois isolados (1,3\%) eram mui- 
to pouco produtores de $\mathrm{H}_{2} \mathrm{~S}$ (resultado $\leq 1$ em BiGGY Agar). As leveduras não Saccharomyces, cujas colônias apresentaram majoritariamente $(85,5 \%)$ coloração marrom claro (2) a preto (4) quando cultivadas em BiGGY Agar, foram significativamente $(\mathrm{P}<0,001)$ mais produtoras de $\mathrm{H}_{2} \mathrm{~S}(2,73 \pm 0,09)$ que os isolados Saccharomyces $(2,22 \pm 0,06)$. Também STRAUSS et al. [17] verificaram que as leveduras não Saccharomyces de origem enológica apresentam majoritariamente elevado potencial para produzir $\mathrm{H}_{3} \mathrm{~S}$. MENDES-FERREIRA, MENDES-FAIA \& LEÃO [10] também estudaram a presença de atividade sulfito redutase em estirpes Saccharomyces cerevisiae comerciais e em leveduras não Saccharomyces de origem enológica, tendo verificado uma grande diversidade de resultados tanto para as estirpes do gênero Saccharomyces como para as não Saccharomyces, evidenciando a grande variabilidade desta característica nas leveduras estudadas. Estes resultados justificam o emprego de estirpes não produtoras de sulfeto para a condução das fermentações naindústria.

Os 25 isolados (Tabela 1) com menor atividade sulfito redutase, demonstrado pela pontuação inferior a $2 \mathrm{em}$ meio de cultura BiGGY Agar, foram utilizados para avaliar a influência do meio de cultura na capacidade da estirpe para produzir $\mathrm{H}_{2} \mathrm{~S}$ (Tabela 2).

A análise de variância dos resultados demonstrou a existência de uma interação significativa entre as estirpes e os meios de cultura. A amostra adequou-se bem à análise em componentes principais, visto que, na medida de adequação da amostra, KMO, obteve-se o valor 0,874 . O teste da esfericidade de Barllet indicou um valor de $\lambda^{2}$ igual a 499, 6 com 78 graus de liberdade $(\mathrm{P}<0,001)$ o que leva a rejeitar a hipótese de que não há correlações entre as variáveis iniciais. $\mathrm{Na}$ análise de componentes

TABELA 1 - Estirpes com menor atividade sulfito redutase

\begin{tabular}{ccc}
\hline Estirpe & Espécie & Origem \\
\hline D19 & Pichia anomala & mosto \\
D20 & Candida pulcherrima & mosto \\
F40 & Candida pelliculosa & mosto \\
J71 & Candida pulcherrima & mosto \\
VB52 & Saccharomyces cerevisiae & vinho \\
VB57 & Saccharomyces cerevisiae & vinho \\
VB62 & Saccharomyces cerevisiae & vinho \\
VB63 & Saccharomyces cerevisiae & vinho \\
I78 & Saccharomyces cerevisiae & mosto \\
I80 & Saccharomyces cerevisiae & mosto \\
C84 & Saccharomyces cerevisiae & mosto \\
H86 & Saccharomyces cerevisiae & mosto \\
VC109 & Saccharomyces cerevisiae & vinho \\
VC114 & Saccharomyces cerevisiae & vinho \\
VC117 & Saccharomyces cerevisiae & vinho \\
VC118 & Saccharomyces cerevisiae & vinho \\
VF122 & Saccharomyces cerevisiae & vinho \\
VG139 & Saccharomyces cerevisiae & vinho \\
VA153 & Saccharomyces cerevisiae & vinho \\
VA155 & Saccharomyces cerevisiae & vinho \\
VD162 & Saccharomyces cerevisiae & vinho \\
VD166 & Saccharomyces cerevisiae & vinho \\
VH176 & Saccharomyces cerevisiae & vinho \\
VO256 & Saccharomyces cerevisiae & vinho \\
VO261 & Saccharomyces cerevisiae & vinho \\
\hline & &
\end{tabular}

TABELA 2 - Intensidade de $\mathrm{H}$ S produzido pelas estirpes nos diversos meios de cultura

\begin{tabular}{|c|c|c|c|c|c|c|c|c|c|c|c|c|c|}
\hline \multicolumn{2}{|c|}{ Estirpes BiGGY } & \multirow{2}{*}{$\frac{\text { MS }}{2,0}$} & \multirow{2}{*}{$\frac{\text { M1 }}{0,5}$} & \multirow{2}{*}{$\frac{\mathrm{M} 2}{1,0}$} & \multirow{2}{*}{$\frac{\mathrm{M3}}{1,5}$} & \multirow{2}{*}{$\frac{\mathrm{M} 4}{1,0}$} & \multirow{2}{*}{$\frac{\text { M5 }}{1,0}$} & \multirow{2}{*}{$\begin{array}{c}\text { M6 } \\
1,8\end{array}$} & \multirow{2}{*}{$\begin{array}{l}\text { M7 } \\
0,5\end{array}$} & \multirow{2}{*}{$\frac{\text { M8 }}{1,8}$} & \multirow{2}{*}{$\frac{\text { M9 }}{1,0}$} & \multirow{2}{*}{$\frac{\mathrm{M} 10}{0,5}$} & \multirow{2}{*}{$\frac{\text { M11 }}{0,5}$} \\
\hline$\overline{\mathrm{D} 19}$ & 1,4 & & & & & & & & & & & & \\
\hline D20 & 1,9 & 2,3 & 3,5 & 3,5 & 3,0 & 3,0 & 3,5 & 3,0 & 3,5 & 2,5 & 3,5 & 3,0 & 3,5 \\
\hline F40 & 1,3 & 1,9 & 1,0 & 1,8 & 1,8 & 2,0 & 1,0 & 2,0 & 0,5 & 2,0 & 1,8 & 0,5 & 1,0 \\
\hline J71 & 1,9 & 1,3 & 3,5 & 3,5 & 3,5 & 3,5 & 3,5 & 3,5 & 3,5 & 3,0 & 3,5 & 3,0 & 3,5 \\
\hline VB52 & 1,9 & 2,5 & 1,5 & 2,0 & 2,0 & 2,0 & 2,5 & 2,0 & 2,0 & 1,5 & 1,8 & 1,5 & 2,0 \\
\hline VB57 & 1,5 & 2,0 & 2,0 & 2,0 & 2,0 & 2,0 & 3,0 & 2,0 & 3,0 & 2,0 & 2,0 & 1,8 & 2,0 \\
\hline VB62 & 1,3 & 1,8 & 2,0 & 2,0 & 2,0 & 2,3 & 3,0 & 2,0 & 2,0 & 2,0 & 2,0 & 1,8 & 2,0 \\
\hline VB63 & 1,8 & 2,0 & 1,5 & 2,0 & 1,5 & 2,0 & 2,5 & 2,0 & 2,0 & 1,5 & 1,8 & 1,5 & 1,8 \\
\hline 178 & 1,0 & 1,0 & 1,5 & 1,5 & 1,0 & 1,5 & 0,5 & 1,0 & 1,0 & 1,0 & 1,0 & 0,8 & 1,3 \\
\hline I80 & 1,9 & 1,8 & 1,5 & 2,0 & 1,8 & 2,0 & 2,5 & 1,8 & 2,0 & 1,5 & 1,5 & 1,5 & 1,5 \\
\hline $\mathrm{C} 84$ & 1,6 & 2,0 & 1,8 & 2,0 & 2,0 & 2,0 & 3,0 & 1,8 & 3,0 & 2,0 & 2,0 & 1,8 & 2,0 \\
\hline H86 & 1,9 & 2,4 & 1,8 & 2,0 & 2,0 & 2,0 & 3,0 & 2,0 & 3,0 & 1,8 & 2,0 & 2,0 & 2,0 \\
\hline VC109 & 1,6 & 2,5 & 2,0 & 2,0 & 2,0 & 1,8 & 3,0 & 1,7 & 3,0 & 1,5 & 2,0 & 1,8 & 2,0 \\
\hline VC114 & 1,1 & 2,0 & 2,0 & 2,0 & 2,0 & 2,0 & 3,0 & 2,0 & 3,0 & 2,0 & 2,0 & 1,8 & 2,5 \\
\hline VC117 & 1,2 & 2,0 & 2,0 & 2,0 & 2,0 & 2,0 & 3,0 & 2,0 & 3,0 & 2,0 & 2,0 & 1,8 & 2,3 \\
\hline VC118 & 1,9 & 2,5 & 1,5 & 2,0 & 1,8 & 2,0 & 2,8 & 1,8 & 1,8 & 1,5 & 2,0 & 1,5 & 2,0 \\
\hline VF 122 & 1,9 & 2,5 & 0,5 & 2,0 & 1,8 & 2,0 & 2,5 & 1,8 & 1,8 & 1,5 & 1,8 & 1,5 & 1,8 \\
\hline VG139 & 1,5 & 2,0 & 2,0 & 2,0 & 2,0 & 2,0 & 3,0 & 2,0 & 3,0 & 2,0 & 2,0 & 1,8 & 2,0 \\
\hline VA153 & 1,9 & 2,5 & 1,8 & 2,0 & 2,0 & 1,0 & 3,0 & 1,5 & 3,0 & 1,5 & 1,8 & 1,8 & 2,0 \\
\hline VA 155 & 1,8 & 2,5 & 2,0 & 2,0 & 2,0 & 1,8 & 3,0 & 1,8 & 3,0 & 1,5 & 2,0 & 1,8 & 2,3 \\
\hline VD162 & 1,8 & 2,0 & 1,8 & 2,0 & 2,0 & 1,8 & 3,0 & 1,8 & 3,0 & 1,5 & 1,8 & 1,5 & 2,0 \\
\hline VD166 & 1,9 & 2,3 & 1,5 & 2,0 & 1,8 & 2,0 & 2,5 & 1,8 & 2,0 & 1,8 & 2,0 & 1,5 & 2,0 \\
\hline VH176 & 1,0 & 0,0 & 0,5 & 0,0 & 0,0 & 1,0 & 1,0 & 0,8 & 0,5 & 0,5 & 0,5 & 0,3 & 0,5 \\
\hline VO256 & 1,8 & 1,5 & 0,5 & 1,0 & 0,3 & 0,8 & 1,0 & 0,5 & 1,0 & 0,0 & 0,5 & 0,0 & 0,5 \\
\hline VO261 & 1,7 & 2,0 & 2,0 & 2,0 & 2,0 & 3,0 & 3,0 & 2,0 & 3,0 & 1,8 & 2,0 & 2,5 & 2,5 \\
\hline
\end{tabular}

Cada valor corresponde à média de duas repetições.

principais, a variância dos resultados obtidos nos diferentes meios foi decomposta em dois fatores que explicam $85,2 \%$ da variância inicial. O primeiro componente $(74,2 \%)$ é definido pelos resultados observados nos 11 mostos naturais, enquanto o segundo $(11,0 \%)$, pelos resultados dos outros meios (MS e BiGGY Agar). A Figura 2 ilustra a distribuição das leveduras pelos dois componentes principais.

As estirpes Saccharomyces cerevisiae I78, VB52, VB57, VB62, VB63, I80, C84, H86, VC109, VC114, VC117, VC118, VF122, VG139, VA153, VA155, VD162, VD166, VO261 e Candida pelliculosa F40 são melhor diferenciadas pelos resultados obtidos em mosto sintético e BiGGY Agar, enquanto as estirpes Saccharomyces cerevisiae VO256, Pichia anomala D19 e Candida pulcherrima D20 e J71 são melhor diferenciadas nos mostos naturais (Figura 2). De fato, os mostos naturais parecem ser mais adequados para diferenciar as estirpes não Saccharomyces das Saccharomyces cerevisiae usadas. Podemos ainda destacar a estirpe Saccharomyces cerevisiae VH176 por apresentar menor atividade sulfito redutase em todos os meios utilizados, vindo ao encontro ao objetivo deste trabalho de selecionar uma estirpe pouco produtora de $\mathrm{H}_{2} \mathrm{~S}$.

Os resultados confirmam que a composição do mosto influencia significativamente a capacidade de uma de- 


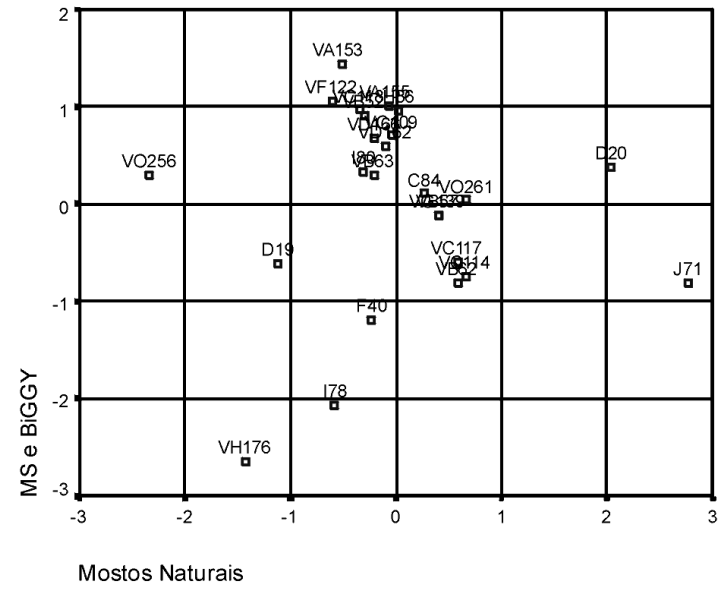

FIGURA 2 - Distribuição dos 25 isolados pelos dois componentes principais

terminada estirpe de levedura produzir ou não $\mathrm{H}_{2} \mathrm{~S}$. Portanto, é razoável admitir-se que o mosto adicionado de citrato de bismuto seja o meio adequado para prever o potencial de uma dada estirpe de levedura produzir $\mathrm{H}_{2} \mathrm{~S}$ num determinado mosto.

\section{4 - CONCLUSÕES}

Os resultados obtidos neste trabalho demonstram que a quantidade de $\mathrm{H}_{2} \mathrm{~S}$ produzida durante a vinificação é influenciada pela estirpe de levedura utilizada e pela composição do mosto. As leveduras não Saccharomyces produziram mais $\mathrm{H}_{2} \mathrm{~S}$ que as leveduras do gênero Saccharomyces. Para além da grande variabilidade entre leveduras, relativamente a sua capacidade de formação de sulfeto, também a composição do mosto influencia significativamente a capacidade de uma determinada estirpe de levedura produzir ou não $\mathrm{H}_{2} \mathrm{~S}$. Por isso, se sugere que o potencial de uma dada estirpe de levedura para produzir $\mathrm{H}_{2} \mathrm{~S}$ num determinado mosto seja previamente avaliado antes da sua inoculação no mosto. Estes resultados justificam o emprego de estirpes não produtoras de sulfeto para a condução das fermentações na indústria.

\section{5 - REFERÊNCIAS BIBLIOGRÁFICAS}

[1] ACREE, T. E.; SONOFF, E .P.; SPLITTSTOESSER, D. F. Effect of yeast strain and type of sulfur compounds on hydrogen sulfide production. Am. J. Enol. Vitic., v.23, n.1, p. 6-9, 1972.

[2] BARNETT. J. A.; PAYNE, R. W.; YARROW, D. Yeast: Characterization and identification. $2^{\mathrm{a}}$ edição, Cambrigde University Press. 1990.

[3] ESCHENBRUCH, R. Sulfite and sulfide formation during winemaking A Review. Am. J. Enol. Vitic., v.25, n.3, p.157-161, 1974.

[4] GIUDICI, P.; KUNKEE, R. E. The effect of nitrogen deficiency and sulfur-containing amino acids on the reduction of sulfate to hydrogen sulfide by wine yeasts. Am. J. Enol. Vitic., v.45 n.1, p.107-112, 1994.

[5] HALLINAN, C. P.; SAUL, D. J.; JIRANEK, V. Differential utilizations of sulfur compounds for $\mathrm{H}_{2} \mathrm{~S}$ liberation by nitrogen-starved wine yeasts. Aust. J. Grape Wine Res., v.5, p.82-90, 1999.

[6] HENSCHKE, P. A.; JIRANEK, V. Hydrogen sulfide formation during fermentation: effect of nitrogen composition in model grape must. Proocedings of the International Symposium on Nitrogen in Grapes and Wine, Seatle, USA, 18 e 19 de junho de 1991, p. 172-184.

[7] HENSCHKE, P. A.; JIRANEK, V. Yeasts Metabolism of nitrogen compounds. In: FLEET G. H. (ed). Wine microbiology and biotechnology. Switzerland: Harwood Academic Publishers, 1993, Cap. 4, p.77-164.

[8] JIRANEK, V.; LANGRIDGE, P.; HENSCHKE, P. A. Validation of bismuth-containing indicator media for predicting $\mathrm{H}_{2} \mathrm{~S}$-production potential of Saccharomyces cerevisiae wine yeast under enological conditions. Am. J. Enol. Vitic., v.46, n.2, p.269-273, 1995.

[9] JIRANEK, V.; LANGRIDGE, P.; HENSCHKE, P. A. Determination of sulphide reductase activity and its reponse to assimilable nitrogen status in a commercial Saccharomyces cerevisiae wine yeast. J. App1. Bacteriol., v.81, p.329-336, 1996.

[10] MENDES-FERREIRA, A.; MENDES-FAIA, A.; LEÃO, C. Survey of hydrogen sulphide production by wine yeasts. J. Food Prot., v.64, n.6, p.1033-1037, 2002.

[11] RANKINE, B.C. Nature, origin and prevention of hydrogen sulphide aroma in wines. J. Sci. Fd. Agric., v.14, p.79-91, 1963.

[12] RANKINE, B.C. Hydrogen sulphide production by yeast. J. Sci. Fd. Agric., v. 15, p.872-877, 1964.

[13] RAUHUT, D. Yeasts Production of sulfur compounds. In: FLEET G. H. (ed). Wine microbiology and biotechnology. Switzerland: Harwood Academic Publishers, 1993, Cap. 6, p.182-223.

[14] RENCHER, ALVIN C. - Methods of multivariate analysis. New York: JOHN WILEY \& SONS, COP. XVI, 627 P.. 1995.

[15] SHÜTZ, M.; KUNKEE, R. E. Formation of hydrogen sulfide from elemental sulfur during fermentation by wine yeast. Am. J. Enol. Vitic., v.28, n.3, p.137-144, 1977.

[16] SPIROPOULOS, A.; TANAKA, J.; FLERIANOS, I.; BISSON, L. Characterization of hydrogen sulfide formation in commercial and natural wine isolation of Saccharomyces. Am. J. Enol. Vitic., v.51,n.3, p.233248, 2000.

[17] STRAUSS, M. L. A.; JOLLY, N. P.; LAMBRECHTS, M. G.; VAN RENSBURG, P. Screening for the production of extracellular hydrolytic enzymes by non-Saccharomyces wine yeasts. J. Appl. Microbiol., v.91, p. 182-192, 2001.

[18] VOZ, P. J.; GRAY, R. S. The origin and control of hydrogen sulfide during fermentation of grape must. Am. J. Enol. Vitic., v.30, n.3, p.187-197, 1979.

[19] ZAMBONELLI, C. Richerche biometriche sulla produzione di hidrogeno solforato in Saccharomyces cerevisiae. Ann. Microbiol., v14, p. 129-135, 1964.

[20] ZAMBONELLI, C.; SOLLI, M. G., GUERRA, D. A study of $\mathrm{H}_{2} \mathrm{~S}$ non-producing strains of wine yeasts. Ann. Microbiol., v.34, p.7-15, 1984. 